\title{
Estirpes de Bradyrhizobium em simbiose com guandu-anão em casa de vegetação e no campo
}

\author{
Márcia Rufini( ${ }^{(1)}$, Dâmiany de Pádua Oliveira(2), André Trochmann ${ }^{(1)}$, Bruno Lima Soares ${ }^{(2)}$, \\ Messias José Bastos de Andrade ${ }^{(2)}$ e Fatima Maria de Souza Moreira ${ }^{(1)}$
}

(1)Universidade Federal de Lavras (Ufla), Departamento de Ciência do Solo, Caixa Postal 3.037, CEP37200-000 Lavras, MG, Brasil. E-mail: marciarufini@gmail.com, trochmann@gmail.com, fmoreira@dcs.ufla.br (2)Ufla, Departamento de Agricultura. E-mail: damy_agro84@hotmail.com, brunolsoares@gmail.com, mandrade@dag.ufla.br

Resumo - O objetivo deste trabalho foi avaliar a eficiência simbiótica de estirpes de bactérias fixadoras de nitrogênio do gênero Bradyrhizobium com guandu-anão. Os experimentos foram conduzidos em vasos de Leonard, em vasos com solo e em campo. Foram testadas 11 estirpes em vasos de Leonard, e as que apresentaram maior eficiência em promover o crescimento do guandu-anão foram avaliadas em vasos com solo (Latossolo Vermelho-Amarelo e Cambissolo) e em campo (Latossolo Vermelho-Amarelo). Em todos os experimentos, os tratamentos foram comparados a dois controles positivos (estirpes aprovadas como inoculantes para as cultivares de guandu-anão BR 2003 e BR 2801) e a duas testemunhas sem inoculação, uma com alta concentração de N mineral, e a outra, a depender do experimento, sem $\mathrm{N}$ mineral (solo) ou com baixa concentração de $\mathrm{N}$ (vasos de Leonard). Algumas estirpes proporcionaram crescimento vegetal semelhante ou superior às estirpes-referência $\mathrm{e}$ às testemunhas em vaso de Leonard. Em vasos com solo, o tipo de solo influenciou os tratamentos. No campo, não houve diferença entre os tratamentos, e as estirpes nativas promoveram bom crescimento. $\mathrm{O}$ guandu-anão é capaz de estabelecer associação simbiótica com bactérias fixadoras de $\mathrm{N}_{2}$, e a estirpe UFLA 03-320 apresenta potencial para ser recomendada para a cultura junto com a estirpe BR 2801.

Termos para indexação: Cajanus cajan, fixação biológica de nitrogênio, inoculante.

\section{Bradyrhizobium strains in symbiosis with dwarf pigeon pea under greenhouse and field conditions}

\begin{abstract}
The objective of this work was to evaluate the symbiotic efficiency of nitrogen-fixing bacterial strains, from the genus Bradyrhizobium, with dwarf pigeon pea. The experiments were carried out in Leonard jars, in pots with soil and in the field. In Leonard jars, 11 strains were tested, and the most effective in promoting pigeon pea growth were evaluated in pots with soil (Oxisol and Cambisol) and in the field (Oxisol). In all experiments, treatments were compared to two positive controls (strains approved as inoculants for pigeon pea cultivars, BR 2003 and BR 2801) and to two controls without inoculation, one with a high concentration of mineral $\mathrm{N}$, and the other, depending on the experiment, without mineral $\mathrm{N}$ (soil) or with low $\mathrm{N}$ concentration (Leonard jars). Some strains have provided plant growth similar or superior to the reference strains and to the controls in Leonard jars. In the pot experiment with soil, the soil type influenced the treatments. In the field, there was no difference among treatments, and the native strains promoted a good plant growth. Dwarf pigeon pea is able to establish a symbiotic association with nitrogen-fixing bacteria, and the strain UFLA 03-320 has the potential to be recommended for this crop together with the BR 2801 strain.
\end{abstract}

Index terms: Cajanus cajan, biological nitrogen fixation, inoculants.

\section{Introdução}

O guandu [Cajanus cajan (L.) Millsp.], é originário da África, pertence à família Fabaceae e é cultivado em 5,32 milhões de hectares, com produção anual de 4,33 milhões de toneladas e produtividade média de grãos de 1.354,9 $\mathrm{kg} \mathrm{ha}^{-1}$ (Food and Agriculture
Organization of the United Nations, 2012). Atualmente, a Índia é seu maior produtor, com 3,86 milhões de hectares e $73 \%$ da produção mundial de grãos. No Brasil, o guandu é cultivado em associação com outras culturas, em áreas não irrigadas de agricultura de subsistência de regiões semiáridas, onde é utilizado na alimentação humana e animal (Souza et al., 2007). 
É uma opção para a região Nordeste do Brasil, pelo seu elevado valor nutritivo, capacidade de resistir à baixa precipitação pluvial e adaptação a solos salinos e de baixa fertilidade (Paz et al., 2000). Além disso, associa-se a bactérias fixadoras de nitrogênio nodulíferas (BFNN) e pode receber a maior parte do $\mathrm{N}$ para seu desenvolvimento da fixação biológica de N (FBN) (Fernandes \& Fernandes, 2000; Paz et al., 2000; Fernandes et al., 2003), o que também indica seu potencial como adubo verde.

No contexto atual, a FBN tem considerável importância econômica e ambiental, pois reduz os custos com fertilizantes nitrogenados e, consequentemente, $o$ alto consumo de combustível utilizado na fabricação destes, além de minimizar o impacto ambiental causado pelo uso intensivo e inadequado desses fertilizantes (Moreira \& Siqueira, 2006). Um dos grandes desafios para o uso da FBN é obter um manejo adequado da simbiose e aumentar sua eficiência.

O guandu é uma leguminosa altamente promíscua, capaz de nodular com BFNN de crescimento lento e rápido. Poth et al. (1986) estimaram, por meio de diluição isotópica de ${ }^{15} \mathrm{~N}$, a quantidade de $\mathrm{N}$ fixado biologicamente na simbiose com guandu e efetivamente incorporado ao solo, e obtiveram de 144 a $179 \mathrm{~kg} \mathrm{ha}^{-1}$, conforme a estirpe de BFNN utilizada. As duas estirpes de BFNN aprovadas como inoculantes pelo Ministério da Agricultura, Pecuária e Abastecimento - Mapa (Brasil, 2011) pertencem ao gênero de crescimento lento Bradyrhizobium: BR 2003 (SEMIA 6156) e BR 2801 (SEMIA 6157). Em outro trabalho conduzido na Índia, Anand \& Dogra (1997), ao avaliar a eficiência de diferentes estirpes de Rhizobium spp. e Bradyrhizobium spp., de crescimento rápido e lento, respectivamente, em cultivares de guandu, em vasos de Leonard modificados, observaram que as estirpes de Bradyrhizobium spp. foram superiores a todas as estirpes de Rhizobium spp.

Bradyrhizobium tem a vantagem de ser mais estável do que outros gêneros de bactérias fixadoras de $\mathrm{N}_{2}$, pois os genes relacionados ao estabelecimento (genes nod) e funcionamento da simbiose (genes nif) estão localizados em cromossomo e não em plasmídeos que podem ser perdidos em condições ambientais estressantes. A maioria das estirpes de BFNN, aprovadas para espécies florestais, adubo verde, forrageiras e para grãos, pertence a esse gênero, e muitas já são usadas com sucesso há décadas, sem a perda de suas propriedades simbióticas, como as de soja e de feijão-caupi. Para uso com feijão-caupi, têm sido relatadas novas estirpes eficientes de Bradyrhizobium (Guimarães et al., 2012; Costa et al., 2013; Jaramillo et al., 2013), o que pode ser extrapolado também para guandu.

A presença de BFNN nativas, pouco efetivas na FBN e que podem competir com as estirpes inoculadas podem limitar os efeitos da inoculação no guandu. Outros fatores, como tipo de solo e diferentes cultivares, podem também influenciar o processo da FBN (Nautiyal et al., 1988; Bidlack et al., 2001). De acordo com Nautiyal et al. (1988), esses fatores podem ser os responsáveis pela pobre nodulação e baixa resposta do guandu à inoculação.

Em razão da diversidade climática e edáfica dos agroecosistemas do Brasil e, ainda, da ausência dos resultados publicados que motivaram a indicação das estirpes de BFNN atualmente aprovadas pelo Mapa, torna-se de fundamental importância a seleção de estirpes inoculantes que permitam o sucesso do manejo da simbiose entre BFNN e guandu, em condições climáticas e edáficas específicas, bem como a constatação da eficiência das estirpes atualmente aprovadas.

O objetivo deste trabalho foi avaliar a eficiência simbiótica de estirpes de bactérias fixadoras de nitrogênio, do gênero Bradyrhizobium, com guandu-anão.

\section{Material e Métodos}

O ensaio para a avaliação da eficiência simbiótica das estirpes de BFNN em guandu foi realizado em condições axênicas de vasos de Leonard (Vincent, 1970), em vasos com solo e em campo. Foi utilizada a cultivar de guandu-anão Iapar 43 (Aratã), de ciclo curto e menor altura, desenvolvida para a produção de grãos para alimentação animal e humana.

O ensaio em vasos de Leonard foi realizado no Setor de Biologia, Microbiologia e Processos Biológicos do Solo, do Departamento de Ciência do Solo, da Universidade Federal de Lavras, de 10/8 a 10/10/2012. Foram testadas sete estirpes do gênero Bradyrhizobium, que fazem parte da coleção do referido Setor e se mostraram eficientes em fixar o $\mathrm{N}_{2}$ em outras espécies leguminosas como siratro e feijão-caupi (Tabela 1). Além destas, também foram testadas estirpes de 
Bradyrhizobium já aprovadas como inoculantes para a cultura da soja (BR 29 ou SEMIA 5019) e do feijão-caupi (UFLA 03-84 ou SEMIA 6461, INPA 03-11b ou SEMIA 6462 e BR 3267 ou SEMIA 6463). Informações relevantes sobre cada estirpe encontramse na Tabela 1.

Utilizou-se o delineamento experimental inteiramente casualizado, com três repetições e 15 tratamentos. Os tratamentos constituíram-se de: inoculação individual das estirpes; comparação com duas testemunhas consideradas controles positivos (estirpes-referência, aprovadas como inoculantes para guandu, BR 2003 e BR 2801); além de duas testemunhas sem inoculação, uma com alta concentração de $\mathrm{N}$ mineral, e outra com baixa concentração de $\mathrm{N}$ mineral para, respectivamente, verificação de condições adequadas de crescimento vegetal e controle de possível contaminação.

A parte superior dos vasos de Leonard continha uma mistura 1:1 de areia e vermiculita, e a inferior, solução nutritiva de Hoagland \& Arnon (1950) modificada. Após o preparo, os vasos foram autoclavados por uma hora, à pressão de $1,5 \mathrm{~kg} \mathrm{~cm}^{-2}$, a $127^{\circ} \mathrm{C}$. Nos tratamentos que receberam inoculação e na testemunha com baixa concentração de $\mathrm{N}$ mineral $\left(5,25 \mathrm{mg} \mathrm{L}^{-1} \mathrm{de} \mathrm{N}\right)$, que não inibe a $\mathrm{FBN}$, a solução nutritiva apresentou a seguinte composição por litro: $0,4 \mathrm{~mL}$ de $236,16 \mathrm{~g}$ $\mathrm{L}^{-1} \mathrm{Ca}\left(\mathrm{NO}_{3}\right)_{2} \cdot 4 \mathrm{H}_{2} \mathrm{O} ; 0,6 \mathrm{~mL}$ de $101,11 \mathrm{~g} \mathrm{~L}^{-1} \mathrm{KNO}_{3}$; $0,1 \mathrm{~mL}$ de $115,03 \mathrm{~g} \mathrm{~L} \mathrm{~L}^{-1} \mathrm{NH}_{4} \mathrm{H}_{2} \mathrm{PO}_{4} ; 2,0 \mathrm{~mL}$ de 246,9 g L-1 $\mathrm{MgSO}_{4} .7 \mathrm{H}_{2} \mathrm{O}$; 3, $0 \mathrm{~mL}$ de 87, $13 \mathrm{~g} \mathrm{~L}^{-1} \mathrm{~K}_{2} \mathrm{SO}_{4}$; $10,0 \mathrm{~mL}$ de $12,6 \mathrm{~g} \mathrm{~L}^{-1} \mathrm{Ca}\left(\mathrm{H}_{2} \mathrm{PO}_{4}\right)_{2} \cdot \mathrm{H}_{2} \mathrm{O} ; 200,0 \mathrm{~mL}$ de $1,72 \mathrm{~g} \mathrm{~L}^{-1} \mathrm{CaSO}_{4} \cdot 2 \mathrm{H}_{2} \mathrm{O} ; 1,0 \mathrm{~mL}$ de Fe-EDTA e $1,0 \mathrm{~mL}$ de solução suplementar $\left(2,86 \mathrm{~g} \mathrm{~L}^{-1} \mathrm{H}_{3} \mathrm{BO}_{3}\right.$; $1,81 \mathrm{~g} \mathrm{~L}^{-1} \quad \mathrm{MnCl}_{2} \cdot 4 \mathrm{H}_{2} \mathrm{O} ; 0,22 \mathrm{~g} \mathrm{~L}^{-1} \mathrm{ZnSO}_{4} \cdot 7 \mathrm{H}_{2} \mathrm{O}$; $0,08 \mathrm{~g} \mathrm{~L}^{-1} \mathrm{CuSO}_{4} \cdot 5 \mathrm{H}_{2} \mathrm{O}$; e $0,02 \mathrm{~g} \mathrm{~L}^{-1} \mathrm{H}_{2} \mathrm{MoO}_{4} \cdot \mathrm{H}_{2} \mathrm{O}$ ). No tratamento que recebeu alta concentração de $\mathrm{N}$ mineral $\left(52,5 \mathrm{mg} \mathrm{L}^{-1} \mathrm{~N}\right)$, foi utilizada a solução completa, com a seguinte composição por litro: $4,0 \mathrm{~mL}$ de 236,16 g L-1 $\mathrm{Ca}\left(\mathrm{NO}_{3}\right)_{2} \cdot 4 \mathrm{H}_{2} \mathrm{O} ; 6,0 \mathrm{~mL}$ de $101,11 \mathrm{~g} \mathrm{~L}^{-1}$ $\mathrm{KNO}_{3} ; 1,0 \mathrm{~mL}$ de $115,03 \mathrm{~g} \mathrm{~L}^{-1} \mathrm{NH}_{4} \mathrm{H}_{2} \mathrm{PO}_{4} ; 2,0 \mathrm{~mL}$ de 246,9 $\mathrm{g} \mathrm{L}^{-1} \mathrm{MgSO}_{4} .7 \mathrm{H}_{2} \mathrm{O} ; 1,0 \mathrm{~mL}$ de Fe-EDTA e $1,0 \mathrm{~mL}$ de solução suplementar $\left(2,86 \mathrm{~g} \mathrm{~L}^{-1} \mathrm{H}_{3} \mathrm{BO}_{3}\right.$; $1,81 \mathrm{~g} \mathrm{~L}^{-1} \mathrm{MnCl}_{2} \cdot 4 \mathrm{H}_{2} \mathrm{O} ; 0,22 \mathrm{~g} \mathrm{~L}^{-1} \mathrm{ZnSO}_{4} \cdot 7 \mathrm{H}_{2} \mathrm{O} ; 0,08 \mathrm{~g}$ $\mathrm{L}^{-1} \mathrm{CuSO}_{4} \cdot 5 \mathrm{H}_{2} \mathrm{O}$; e $0,02 \mathrm{~g} \mathrm{~L}^{-1} \mathrm{H}_{2} \mathrm{MoO}_{4} \cdot \mathrm{H}_{2} \mathrm{O}$ ). Ambas as soluções foram autoclavadas por $40 \mathrm{~min}$, a $1,5 \mathrm{~kg} \mathrm{~cm}^{-2}$ e a $127^{\circ} \mathrm{C}$, antes de serem colocadas nos vasos.

As sementes foram desinfestadas superficialmente com álcool etílico a $96 \%$ v/v por 30 s e hipoclorito de sódio a $2 \%$ por 2 min. Em seguida, as sementes foram lavadas seis vezes com água esterilizada, para retirada de resíduos dos tratamentos anteriores. Após esses procedimentos, as sementes foram

Tabela 1. Origem e características das estirpes de Bradyrhizobium testadas.

\begin{tabular}{|c|c|c|c|c|c|}
\hline \multirow[t]{2}{*}{ Estirpe } & \multicolumn{3}{|c|}{ Origem } & \multirow[t]{2}{*}{ Eficiência simbiótica $^{(1)}$} & \multirow[t]{2}{*}{ Fonte/referência ${ }^{(2)}$} \\
\hline & Estado/região & Sistema de uso da terra & Planta hospedeira & & \\
\hline UFLA03-153 & Minas Gerais & Mineração de bauxita & Vigna unguiculata & V. unguiculata $(\mathrm{E})$ & SBMPBS-Ufla/(Soares et al., 2014) \\
\hline UFLA03-154 & Minas Gerais & Mineração de bauxita & V. unguiculata & V. unguiculata $(\mathrm{E})$ & SBMPBS-Ufla/(Soares et al., 2014) \\
\hline UFLA03-164 & Minas Gerais & Mineração de bauxita & V. unguiculata & V. unguiculata $(\mathrm{E})$ & SBMPBS-Ufla/(Soares et al., 2014) \\
\hline UFLA03-320 & Minas Gerais & Agricultura & V. unguiculata & V. unguiculata $(\mathrm{E})$ & SBMPBS-Ufla/(Rufini et al., 2014) \\
\hline UFLA03-321 & Minas Gerais & Agricultura & V. unguiculata & V. unguiculata $(\mathrm{E})$ & SBMPBS-Ufla/(Rufini et al., 2014) \\
\hline UFLA03-325 & Minas Gerais & Agricultura & V. unguiculata & V. unguiculata $(\mathrm{E})$ & SBMPBS-Ufla/(Rufini et al., 2014) \\
\hline UFLA04-212 & Amazônia & Agricultura & Macroptilium atropurpureum & M. atropurpureum $(\mathrm{E})$ & SBMPBS-Ufla/(Florentino et al., 2009) \\
\hline INPA 03-11b & Amazônia & Capoeira & Centrosema sp. & V. unguiculata $(\mathrm{R})$ & SBMPBS-UFLA/(Soares et al., 2006) \\
\hline UFLA 03-84 & Rondônia & Pastagem & V. unguiculata & V. unguiculata $(\mathrm{R})$ & SBMPBS-UFLA/(Soares et al., 2006) \\
\hline BR 3267 & Semiárido & - & V. unguiculata & V. unguiculata $(\mathrm{R}) \mathrm{I}$ & Embrapa Agrobiologia/(Martins et al., 2003) \\
\hline BR 29 & Rio de Janeiro & - & - & Glycine $\max (\mathrm{R})$ & CNPAB-(Peres \& Vidor, 1980) \\
\hline BR2801 & Rio de Janeiro & - & Crotalaria spp. & Cajanus cajan $(\mathrm{R})$ & Embrapa Agrobiologia(Brasil, 2011) \\
\hline BR2003 & Brasília & - & Stylosantes spp. & C. cajan $(\mathrm{R})$ & Embrapa Agrobiologia(Brasil, 2011) \\
\hline
\end{tabular}

${ }^{(1)} \mathrm{E}$, eficiente (massa de matéria seca da parte aérea do tratamento, com inoculação da estirpe testada = testemunha sem inoculação, que recebeu $\mathrm{N}$ mineral); R, aprovada como inoculante para Vigna unguiculata (UFLA03-84, INPA03-11b e BR3267), Glycine max (BR 29) e Cajanus cajan (BR2801, BR2003), pelo Ministério da Agricultura, Pecuária e Abastecimento. ${ }^{(2)}$ SBMPBS-UFLA, Coleção de Bactérias do Setor de Biologia, Microbiologia e Processos Biológicos do Solo, da Universidade Federal de Lavras. 
imersas em água destilada por duas horas, para ficarem embebidas de água e garantir a germinação. Posteriormente, as sementes foram postas a germinar em placas de Petri, que continham papel filtro e algodão umedecido e esterilizado, e colocadas em câmara de crescimento a $28^{\circ} \mathrm{C}$, por 24 horas. Após este período, foram semeadas quatro sementes pré-germinadas por vaso e, posteriormente, foi realizada a inoculação com $1,0 \mathrm{~mL}$ do meio de cultura 79 líquido (Fred \& Waksman, 1928) colocado junto a cada semente. Os isolados foram cultivados sob agitação por aproximadamente 120 horas e continham aproximadamente $10^{8}$ células de BFNN mL ${ }^{-1}$. Para evitar contaminação, colocouse sobre a superfície do vaso uma fina camada de mistura esterilizada de areia, clorofórmio e parafina.

O nível de solução nutritiva nos vasos foi mantido, com reposição periódica. Até aos 45 dias após o plantio, os vasos receberam solução nutritiva com $1 / 4$ de força iônica. A partir desse período, aumentou-se a força da solução nutritiva para 1/3. Após a emergência, realizou-se o desbaste, tendo-se deixado duas plantas por vaso. As plantas foram colhidas aos 60 dias, tendose avaliado o número de nódulos $(\mathrm{NN})$, a matéria seca de nódulos (MSN), a matéria seca da raiz (MSR) e da parte aérea (MSPA), o teor (TNPA) e o acúmulo (ANPA) de $\mathrm{N}$ na parte aérea, a eficiência relativa (ER) e a altura da planta.

As estirpes mais eficientes (UFLA 03-320 e UFLA 03-321) no experimento com vasos de Leonard, além da estirpe BR 29, aprovada como inoculante para soja, foram selecionadas para testes em vasos com solo e campo.

O experimento em vasos com solo foi realizado em casa de vegetação, no Departamento de Ciência do Solo da Ufla, de 23/1 a 17/5/2013. Foram coletados solos da camada arável, em dois locais distintos - Luminárias e Lavras. As amostras de solo foram destorroadas, homogeneizadas e passadas em peneira de $4 \mathrm{~mm}$, antes de serem usadas como substrato. Os vasos utilizados tinham capacidade de $1,6 \mathrm{dm}^{3}$.

Os solos de Luminárias $\left(21^{\circ} 32^{\prime} \mathrm{S}\right.$ e $\left.44^{\circ} 57^{\prime} \mathrm{W}\right)$ e Lavras $\left(21^{\circ} 12^{\prime} \mathrm{S}, 44^{\circ} 58^{\prime} \mathrm{W}\right)$ foram classificados como Cambissolo e Latossolo Vermelho-Amarelo, respectivamente, ambos de textura argilosa. Esses solos tinham histórico de cultivo com milho, e não havia registro de uso de inoculantes. A população nativa em ambos era de aproximadamente
$10^{3}$ UFC $^{-1}$ de solo. O Cambissolo e o Latossolo Vermelho-Amarelo apresentaram os seguintes atributos químicos e físicos, respectivamente : $\mathrm{pH}$ em água, 4,6 e 5,9; P (Mehlich I), 0,56 e 5,81 $\mathrm{mg} \mathrm{dm}^{-3}$; $\mathrm{K}, 68$ e $128 \mathrm{mg} \mathrm{dm}^{-3}$; Ca, 0,4 e 3,5 $\mathrm{cmol}_{\mathrm{c}} \mathrm{dm}^{-3}$; $\mathrm{Mg}, 0,2$ e $1,1 \mathrm{cmol}_{\mathrm{c}} \mathrm{dm}^{-3} ; \mathrm{Al}, 0,8$ e $0,1 \mathrm{cmol}_{\mathrm{c}} \mathrm{dm}^{-3}$; $\mathrm{H}+\mathrm{Al}, 5,05$ e 4,04 $\mathrm{cmol}_{\mathrm{c}} \mathrm{dm}^{-3}$; soma de bases, 0,77 e 4,93 $\mathrm{cmol}_{\mathrm{c}} \mathrm{dm}^{-3} ; \mathrm{T}, 5,82$ e $8,97 \mathrm{cmol}_{\mathrm{c}} \mathrm{dm}^{-3} ; \mathrm{t}, 1,57$ e $5,03 \mathrm{cmol}_{\mathrm{c}} \mathrm{dm}^{-3}$; saturação por alumínio, 50,96 e 1,99\%; saturação por bases, 13,31 e 54,94\%; matéria orgânica, 3,41 e 2,61 dag kg-1; areia, 400 e $590 \mathrm{~g} \mathrm{~kg}^{-1}$; silte, 250 e $70 \mathrm{~g} \mathrm{~kg}^{-1}$; e argila, 350 e $340 \mathrm{~g} \mathrm{~kg}^{-1}$.

$\mathrm{O}$ delineamento experimental em blocos ao acaso foi utilizado com quatro repetições, em arranjo fatorial $7 \times 2$, com sete tratamentos e dois tipos de solo. Os sete tratamentos foram: inoculação com as estirpes UFLA 03-320, UFLA 03-321 e BR 29, além das estirpes aprovadas como inoculante para guandu (BR 2003 e BR 2801), e das testemunhas sem inoculação, com ou sem adubação com $\mathrm{N}$ mineral. Em todas as parcelas, foi efetuada uma adubação com $300,300,40,0,8,1,5,3,6,5,0$ e $0,15 \mathrm{mg} \mathrm{dm}^{-3} \mathrm{de}$ $\mathrm{K}, \mathrm{P}, \mathrm{S}, \mathrm{B}, \mathrm{Cu}, \mathrm{Mn}, \mathrm{Zn}$ e Mo, respectivamente (Malavolta et al., 1989). A testemunha com $\mathrm{N}$ mineral recebeu $300 \mathrm{mg} \mathrm{dm}^{-3}$ de $\mathrm{N}$, fonte $\mathrm{NH}_{4} \mathrm{NO}_{3}$, parcelados em três aplicações.

As sementes de guandu-anão 'Iapar 43' (Aratã) foram desinfestadas e germinadas conforme a metodologia descrita no ensaio com vasos de Leonard. Foram semeadas quatro sementes pré-germinadas por vaso, e cada uma recebeu $1,0 \mathrm{~mL}$ do inóculo (aproximadamente $10^{8}$ células de BFNN $\mathrm{mL}^{-1}$ ), cultivado em meio 79 líquido. Após a emergência, foi feito o desbaste, tendo-se deixado duas plântulas por vaso.

As plantas foram colhidas no período da floração (aproximadamente aos 120 dias após emergência), para avaliação das seguintes variáveis: número de nódulos $(\mathrm{NN})$, matéria seca de nódulos (MSN), matéria seca da parte área (MSPA), eficiência relativa (ER), teor (TNPA) e acúmulo (ANPA) de $\mathrm{N}$ na parte aérea e altura da planta.

O ensaio de campo foi instalado no Centro de Desenvolvimento Científico e Tecnológico em Agropecuária da Ufla, de 28/11/2012 a 2/4/2013. Os dados de temperatura média e precipitação, no período do experimento, foram de $21,6^{\circ} \mathrm{C}$ e $883,4 \mathrm{~mm}$, respectivamente. Utilizou-se o delineamento experi- 
mental de blocos ao acaso com quatro repetições e sete tratamentos. Os tratamentos foram: inoculação com as estirpes UFLA 03-320, UFLA 03-321, BR 29, mais as estirpes BR 2003 e BR 2801, além das testemunhas sem inoculação, com ou sem $\mathrm{N}$ mineral.

$\mathrm{O}$ inoculante foi preparado com turfa esterilizada, à proporção de $3: 2$ de turfa e culturas em meio 79 líquido, que continham aproximadamente $10^{8}$ células de BFNN $\mathrm{mL}^{-1}$. Utilizaram-se $250 \mathrm{~g}$ do inoculante para cada $10 \mathrm{~kg}$ de sementes. As parcelas foram constituídas por seis linhas de $5 \mathrm{~m}$ de comprimento, espaçadas em $0,50 \mathrm{~m}$, o que totalizou $15 \mathrm{~m}^{2}$ de área total e $5 \mathrm{~m}^{2}$ de área útil (duas linhas destinadas à colheita dos grãos).

Após a demarcação dos sulcos, todos os tratamentos receberam adubação fosfatada e potássica à base de $90 \mathrm{~kg} \mathrm{ha}^{-1}$ de $\mathrm{P}_{2} \mathrm{O}_{5}$ e $50 \mathrm{~kg} \mathrm{ha}^{-1}$ de $\mathrm{K}_{2} \mathrm{O}$, tendo-se utilizado como fontes o superfosfato triplo e o cloreto de potássio, respectivamente. Além desta adubação, a testemunha nitrogenada recebeu $70 \mathrm{~kg} \mathrm{ha}^{-1}$ de $\mathrm{N}$ (fonte ureia), parcelados em duas vezes: $35 \mathrm{~kg} \mathrm{ha}^{-1}$ de $\mathrm{N}$ aplicados à época de semeadura, e $35 \mathrm{~kg} \mathrm{ha}^{-1}$ de $\mathrm{N}$ aos 35 dias após a emergência. A semeadura foi realizada imediatamente após a inoculação, à densidade de 15 sementes por metro. O ensaio foi mantido livre de plantas invasoras por meio de capinas manuais. Não houve necessidade de outros tratamentos fitossanitários.

Por ocasião do florescimento, foram coletadas oito plantas de cada parcela, da segunda e terceira linhas, para avaliação de: número e massa de matéria seca de nódulos (NN e MSN, respectivamente); massa de matéria seca da parte aérea (MSPA); eficiência relativa (ER\%); teor (TNPA\%) e acúmulo (ANPA) de N na parte aérea; e a quantidade de $\mathrm{N}$ disponibilizada ( $\mathrm{kg}$ de $\mathrm{N} \mathrm{ha}^{-1}$ ). À época da colheita, que foi realizada na quarta e quinta linhas de cada parcela, tendo-se deixado $1 \mathrm{~m}$ linear de bordadura nas cabeceiras, avaliaram-se: o número de vagens por planta; o número de grãos por vagem; a massa de 100 grãos; o rendimento de grãos; o e teor (TNG\%) e o acúmulo (ANG) de N nos grãos. Para a avaliação do rendimento de grãos, a umidade foi corrigida para $13 \%$.

Em todos os ensaios, a eficiência relativa (ER) foi calculada em relação à produção de MSPA das plantas do tratamento que recebeu $\mathrm{N}$ mineral, por meio da seguinte expressão: $\mathrm{ER}=($ MSPA tratamento $) \times 100 /$ (MSPA da TCN). O teor de $\mathrm{N}$ total foi avaliado pelo método semimicrokjedahl, de acordo com Sarruge \& Haag (1979), tendo-se determinado a percentagem de $\mathrm{N}$ na matéria seca da parte aérea e nos grãos. $\mathrm{O} \mathrm{N}$ acumulado foi calculado por meio da multiplicação da massa de matéria seca da parte aérea ou do rendimento de grãos pelo teor de $\mathrm{N}(\%)$ e divisão do produto por 100.

Todos os dados foram submetidos à análise de variância, com uso do sistema de análise estatística Sisvar (Ferreira, 2011). As médias dos tratamentos foram agrupadas pelo teste de Scott-Knott, a 5\% de probabilidade. Os valores das variáveis número de nódulos $(\mathrm{NN})$ e matéria seca de nódulos (MSN) foram previamente transformados com uso da fórmula $(\mathrm{X}+0,5)^{0,5}$. Realizou-se a correção da produtividade em função do estande, pela análise de covariância para o estande médio, com o programa Genes (Cruz, 2013). Para o cálculo da quantidade de $\mathrm{N}\left(\mathrm{kg} \mathrm{ha}^{-1} \mathrm{~N}\right)$ disponibilizada pela biomassa, utilizou-se o estande médio do ensaio (72 mil plantas por hectare).

\section{Resultados e Discussão}

No ensaio em vasos de Leonard, não se verificou a presença de nódulos na testemunha com baixa concentração de $\mathrm{N}$, o que indica que não houve contaminação do experimento.

Todas as estirpes testadas foram capazes de nodular o guandu-anão, das quais UFLA 03-84, UFLA 03-11B, UFLA 03-154 e UFLA 04-212 apresentaram os maiores valores de número de nódulos, superiores aos das demais estirpes e às estirpes-referência aprovadas como inoculante para o guandu (BR 2003 e BR 2801), porém, estes nódulos não foram muito eficientes em promover o crescimento da planta (MSPA e altura) (Tabela 2).

$\mathrm{Na}$ análise da matéria seca de nódulos, as estirpes BR 29, UFLA 03-84, UFLA 03-11B, UFLA 03-153, UFLA 03-320, UFLA 03-325 e UFLA 04-212 apresentaram os maiores valores e não se agruparam a nenhuma das estirpes-referência. A estirpe-referência BR 2003 apresentou o menor valor de MSN. As estirpes UFLA 03-84, UFLA 03-11B, UFLA 03-153, UFLA 03-320, UFLA 03-321, UFLA 03-325 e UFLA 04-212 induziram os maiores valores de matéria seca de raiz e foram semelhantes à estirpe-referência BR 2801 e superiores às testemunhas e à estirpe -referência BR 2003.

Pesq. agropec. bras., Brasília, v.49, n.3, p.197-206, mar. 2014 DOI: 10.1590/S0100-204X2014000300006 
Os efeitos dos tratamentos foram mais pronunciados na parte aérea do que nas raízes. Quanto à matéria seca da parte aérea, eficiência relativa e altura, as estirpes UFLA 03-320 e UFLA 03-321 foram as mais eficientes em promover o crescimento vegetal, tendo superado os demais tratamentos. As estirpes UFLA 03-84, UFLA 03-11B, UFLA 03-153, UFLA 03-325 e UFLA 04-212, junto com a estirpe-referência BR 2801, foram superiores às demais estirpes, inclusive à BR 2003 e às testemunhas. A testemunha que recebeu alta concentração de $\mathrm{N}$ mineral foi semelhante à estirpe-referência BR 2003; e a testemunha com baixa concentração de $\mathrm{N}$ mineral apresentou os menores valores nestes parâmetros. Os tratamentos que receberam inoculação foram superiores às testemunhas quanto ao teor de $\mathrm{N}$ na parte aérea. Quanto ao acúmulo de $\mathrm{N}$ na parte aérea, as estirpes UFLA 03-84, UFLA 03-320, UFLA 03-321 e UFLA 03-325, junto com a estirpe-referência BR 2801, apresentaram os maiores valores, tendo superado os demais tratamentos, e as testemunhas apresentaram os menores valores.

As estirpes UFLA 03-320 e UFLA 03-321 foram as mais eficientes em promover o crescimento do guandu. Estas estirpes também se mostraram eficientes em promover o crescimento do feijão-caupi (Vigna unguiculata), em condições de casa de vegetação, em vasos de Leonard (Rufini et al., 2014).

Fernandes \& Fernandes (2000) e Fernandes et al. (2003), que testaram BFNN nativas dos tabuleiros costeiros em guandu, encontraram estirpes capazes de estabelecer simbiose efetiva com o guandu em vasos de Leonard, semelhantes às estirpes aprovadas como inoculante usadas no presente ensaio. Carvalho et al. (2008), ao testar a eficiência de estirpes de soja e suas variantes, entre elas a BR 29, em soja, caupi e guandu, observaram que todas nodularam as três espécies de plantas, contudo, apenas para soja, a interação rizóbio-leguminosa mostrou eficiência significativa.

No ensaio em vasos com solo, a interação solo e tratamentos foi significativa para a maioria dos parâmetros estudados, exceto para MSPA e altura, o que indica que o tipo de solo influenciou os tratamentos (Tabela 3). No Cambissolo, as estirpes-referência (BR 2003 e BR 2801) e a estirpe BR 29 apresentaram os maiores valores de $\mathrm{NN}$, seguidas das estirpes UFLA 03-320 e UFLA 03-321. No Latossolo Vermelho-Amarelo, a estirpe BR 2003 não ficou no grupo com os maiores valores de NN. Além das estirpes BR 2801 e BR 29, que apresentaram maior

Tabela 2. Número de nódulos (NN), massa de matéria seca de nódulos (MSN), de raiz (MSR) e de parte aérea (MSPA), eficiência relativa (ER), teor (TNPA) e acúmulo de nitrogênio na parte aérea (ANPA), e altura do guandu-anão cultivar Iapar 43 (Aratã), em vasos de Leonard, nos diferentes tratamentos de fontes de $\mathrm{N}^{(1)}$.

\begin{tabular}{|c|c|c|c|c|c|c|c|c|}
\hline Fonte de N & $\begin{array}{c}\mathrm{NN} \\
\text { por vaso }\end{array}$ & $\begin{array}{c}\text { MSN } \\
\text { (mg por vaso) }\end{array}$ & $\begin{array}{c}\text { MSR } \\
\text { (g por vaso) }\end{array}$ & $\begin{array}{c}\text { MSPA } \\
\text { (g por vaso) }\end{array}$ & $\begin{array}{l}\text { ER } \\
(\%)\end{array}$ & $\begin{array}{c}\text { TNPA } \\
(\%)\end{array}$ & $\begin{array}{c}\text { ANPA } \\
\text { (mg por vaso) }\end{array}$ & $\begin{array}{l}\text { Altura } \\
(\mathrm{cm})\end{array}$ \\
\hline$+\mathrm{N}\left(52,5 \mathrm{mg} \mathrm{L}^{-1}\right)$ & $0 \mathrm{c}$ & $0,0 \mathrm{c}$ & $0,857 \mathrm{~b}$ & $2,500 \mathrm{c}$ & $100,0 \mathrm{c}$ & $1,43 b$ & $36,006 \mathrm{~d}$ & $41,75 \mathrm{c}$ \\
\hline$-\mathrm{N}\left(5,25 \mathrm{mg} \mathrm{L}^{-1}\right)$ & $0 \mathrm{c}$ & $0,0 \mathrm{c}$ & $0,287 b$ & $0,663 d$ & $26,6 \mathrm{~d}$ & $1,82 b$ & $12,376 \mathrm{~d}$ & $23,42 d$ \\
\hline BR2003 & $108 b$ & $75,0 \mathrm{c}$ & $0,570 \mathrm{~b}$ & $1,910 \mathrm{c}$ & $78,1 \mathrm{c}$ & $3,12 \mathrm{a}$ & $59,618 \mathrm{c}$ & $32,38 \mathrm{c}$ \\
\hline BR2801 & $188 b$ & $156,7 \mathrm{~b}$ & $1,197 \mathrm{a}$ & $3,747 b$ & $148,5 b$ & $3,86 \mathrm{a}$ & $144,317 \mathrm{a}$ & $44,75 b$ \\
\hline BR29 & $165 b$ & $245,0 \mathrm{a}$ & $0,470 \mathrm{~b}$ & $2,070 \mathrm{c}$ & $84,2 \mathrm{c}$ & $2,99 \mathrm{a}$ & $61,477 \mathrm{c}$ & $33,00 \mathrm{c}$ \\
\hline UFLA03-84 & $328 \mathrm{a}$ & $371,7 \mathrm{a}$ & $1,107 \mathrm{a}$ & $3,807 b$ & $154,7 b$ & $3,77 \mathrm{a}$ & $142,827 \mathrm{a}$ & $50,75 b$ \\
\hline INPA03-11B & $294 a$ & $435,0 \mathrm{a}$ & $1,170 \mathrm{a}$ & $3,783 b$ & $152,8 b$ & $3,12 \mathrm{a}$ & $118,486 b$ & $50,67 b$ \\
\hline BR3267 & $121 b$ & $210,7 b$ & $0,517 b$ & $2,253 \mathrm{c}$ & $89,6 \mathrm{c}$ & $3,21 \mathrm{a}$ & $72,280 \mathrm{c}$ & $37,58 \mathrm{c}$ \\
\hline UFLA03-153 & $223 b$ & $374,3 \mathrm{a}$ & $1,067 \mathrm{a}$ & $3,430 \mathrm{~b}$ & $139,4 b$ & $3,60 \mathrm{a}$ & $121,026 b$ & $45,83 b$ \\
\hline UFLA03-154 & $285 a$ & $192,3 b$ & $0,770 \mathrm{~b}$ & $2,807 \mathrm{c}$ & $116,1 \mathrm{c}$ & $3,68 \mathrm{a}$ & $102,353 b$ & $39,167 \mathrm{c}$ \\
\hline UFLA03-164 & $197 b$ & $143,7 b$ & $0,623 b$ & $2,367 \mathrm{c}$ & $94,7 \mathrm{c}$ & $3,51 \mathrm{a}$ & $85,328 \mathrm{c}$ & $38,167 \mathrm{c}$ \\
\hline UFLA03-320 & $146 b$ & $292,3 a$ & $1,480 \mathrm{a}$ & $4,683 a$ & $188,0 \mathrm{a}$ & $3,51 \mathrm{a}$ & $164,220 \mathrm{a}$ & $56,25 \mathrm{a}$ \\
\hline UFLA03-321 & $118 b$ & $196,0 \mathrm{~b}$ & $1,447 \mathrm{a}$ & $4,756 a$ & $195,1 \mathrm{a}$ & $3,73 \mathrm{a}$ & $176,861 \mathrm{a}$ & $55,83 a$ \\
\hline UFLA03-325 & $132 b$ & $299,3 a$ & $1,287 \mathrm{a}$ & $3,957 b$ & $162,3 b$ & $3,60 \mathrm{a}$ & $142,398 \mathrm{a}$ & $49,33 b$ \\
\hline UFLA04-212 & $439 a$ & $325,0 \mathrm{a}$ & $0,957 \mathrm{a}$ & $3,397 \mathrm{~b}$ & $138,0 \mathrm{~b}$ & $3,25 \mathrm{a}$ & $108,091 b$ & $46,83 b$ \\
\hline P valor & 0,0000 & 0,0000 & 0,0000 & 0,0000 & 0,0000 & 0,0000 & 0,0000 & 0,0000 \\
\hline CV (\%) & 30,5 & 4,6 & 28,3 & 17,5 & 19,5 & 14,5 & 20,3 & 10,6 \\
\hline
\end{tabular}

${ }^{(1)}$ Médias seguidas de letras iguais, nas colunas, não diferem entre si, pelo teste Scott-Knott, a 5\% de probabilidade. 
nodulação no Cambissolo, a estirpe UFLA 03-320 também proporcionou maior nodulação em guandu no Latossolo Vermelho-Amarelo. A testemunha que recebeu $\mathrm{N}$ mineral não nodulou no Cambissolo e, junto com a testemunha sem $\mathrm{N}$ mineral, apresentou os menores valores. No Latossolo Vermelho-Amarelo, a testemunha que recebeu $\mathrm{N}$ mineral apresentou nódulos, porém em número baixo. A testemunha sem $\mathrm{N}$ mineral apresentou mais nódulos do que a testemunha que recebeu $\mathrm{N}$ mineral, e foi semelhante à estirpe-referência BR 2003 e a estirpe UFLA 03-320.

As estirpes-referência - BR 2003 e BR 2801 - e a estripe UFLA 03-320 apresentaram os maiores valores de MSN no Cambissolo, seguidas pelas estirpes BR 29 e UFLA 03-321, enquanto as testemunhas apresentaram os menores valores. No Latossolo Vermelho-Amarelo, a testemunha $+\mathrm{N}$ foi inferior aos demais tratamentos. No Cambissolo, as testemunhas apresentaram maiores valores de ER do que os tratamentos com inoculação. Quanto ao teor e acúmulo de $\mathrm{N}$ na parte aérea, a testemunha que recebeu $\mathrm{N}$ mineral foi superior aos demais tratamentos. No Latossolo Vermelho-Amarelo, não houve diferença significativa entre os tratamentos quanto aos parâmetros ER, TNPA e ANPA.
Quanto aos parâmetros relativos ao desenvolvimento da planta (ER e ANPA), os tratamentos com inoculação foram inferiores à testemunha $+\mathrm{N}$ no Cambissolo. Isto pode estar relacionado à acidez e à fertilidade do solo, pois, no Latossolo Vermelho-Amarelo, que possui $\mathrm{pH}$ mais elevado e é mais fértil, estes tratamentos foram semelhantes. Um fator estressante para a bactéria e a planta, como a sensibilidade à acidez, pode ter afetado a simbiose. De acordo com Moreira \& Siqueira (2006), o hospedeiro pode ser mais afetado pela acidez do que a bactéria. Plantas sem adubação de $\mathrm{N}$ são mais sensíveis aos estresses ambientais do que plantas que recebem apenas N mineral. Rufini et al. (2011) observaram que a simbiose e o desenvolvimento das plantas de feijoeiro-comum, em solo com e sem calagem, foram favorecidos com a calagem. Portanto, em outros tipos de solo, com características mais favoráveis ao estabelecimento da simbiose com estas estirpes, pode haver respostas positivas à inoculação.

Em relação aos efeitos principais dos tratamentos para MSPA, a testemunha que recebeu $\mathrm{N}$ mineral foi superior aos demais tratamentos, porém quanto à altura, não houve diferença significativa entre os tratamentos (Tabela 4). Entre os dois tipos de solo,

Tabela3. Número de nódulos (NN), massa de matéria seca de nódulos (MSN) e de parte aérea (MSPA), eficiência relativa (ER), teor (TNPA) e acúmulo de nitrogênio na parte aérea (ANPA), e altura em guandu-anão cultivar Iapar 43 (Aratã), para a interação entre solo e tratamentos, em casa de vegetação ${ }^{(1)}$.

\begin{tabular}{|c|c|c|c|c|c|c|c|}
\hline Tratamento & $\begin{array}{c}\mathrm{NN} \\
\text { por vaso }\end{array}$ & $\begin{array}{c}\text { MSN } \\
\text { (mg por vaso) }\end{array}$ & $\begin{array}{c}\text { MSPA } \\
\text { (g por vaso) }\end{array}$ & $\begin{array}{l}\text { ER } \\
(\%)\end{array}$ & $\begin{array}{l}\text { TNPA } \\
(\%)\end{array}$ & $\begin{array}{c}\text { ANPA } \\
\text { (mg por vaso) }\end{array}$ & $\begin{array}{c}\text { Altura } \\
(\mathrm{cm})\end{array}$ \\
\hline & \multicolumn{7}{|c|}{ Cambissolo } \\
\hline$+\mathrm{N}\left(300 \mathrm{mg} \mathrm{dm}^{-3}\right)$ & $0 \mathrm{c}$ & $0,0 \mathrm{c}$ & $6,378 \mathrm{a}$ & $100,0 \mathrm{a}$ & $4,16 \mathrm{a}$ & $259,55 \mathrm{a}$ & $58,33 \mathrm{a}$ \\
\hline$-\mathrm{N}$ & $2 \mathrm{c}$ & $35,3 \mathrm{c}$ & $5,568 \mathrm{a}$ & $89,4 a$ & $2,08 b$ & $115,87 \mathrm{~b}$ & $66,75 \mathrm{a}$ \\
\hline BR2003 & $19 \mathrm{a}$ & $265,5 \mathrm{a}$ & $4,893 \mathrm{a}$ & $77,3 b$ & $2,60 \mathrm{~b}$ & $125,38 b$ & $57,06 \mathrm{a}$ \\
\hline BR2801 & $22 \mathrm{a}$ & $180,5 \mathrm{a}$ & $5,198 \mathrm{a}$ & $82,0 \mathrm{~b}$ & $2,24 b$ & $117,15 b$ & $56,60 \mathrm{a}$ \\
\hline BR29 & $14 \mathrm{a}$ & $111,3 b$ & $4,923 \mathrm{a}$ & $78,7 \mathrm{~b}$ & $1,98 \mathrm{~b}$ & $97,89 \mathrm{~b}$ & $66,80 \mathrm{a}$ \\
\hline UFLA03-320 & $6 \mathrm{~b}$ & $158,0 \mathrm{a}$ & $4,410 \mathrm{a}$ & $68,1 \mathrm{~b}$ & $2,24 b$ & $99,29 \mathrm{~b}$ & $51,38 \mathrm{a}$ \\
\hline \multirow[t]{2}{*}{ UFLA03-321 } & $8 \mathrm{~b}$ & $104,3 b$ & $4,935 \mathrm{a}$ & $77,6 \mathrm{~b}$ & $2,18 \mathrm{~b}$ & $109,70 \mathrm{~b}$ & $62,53 \mathrm{a}$ \\
\hline & \multicolumn{7}{|c|}{ Latossolo Vermelho-Amarelo } \\
\hline$+\mathrm{N}\left(300 \mathrm{mg} \mathrm{dm}^{-3}\right)$ & $7 \mathrm{c}$ & $49,3 \mathrm{~b}$ & $7,013 \mathrm{a}$ & $100,0 \mathrm{a}$ & $2,80 \mathrm{a}$ & $196,54 \mathrm{a}$ & $71,94 a$ \\
\hline$-\mathrm{N}$ & $22 \mathrm{~b}$ & $308,5 \mathrm{a}$ & $5,295 \mathrm{a}$ & $76,6 \mathrm{a}$ & $3,15 \mathrm{a}$ & $166,36 \mathrm{a}$ & $66,06 \mathrm{a}$ \\
\hline BR2003 & $19 \mathrm{~b}$ & $225,3 \mathrm{a}$ & $5,558 \mathrm{a}$ & $77,6 \mathrm{a}$ & $2,76 \mathrm{a}$ & $149,79 \mathrm{a}$ & $68,31 \mathrm{a}$ \\
\hline BR2801 & $41 \mathrm{a}$ & $338,3 \mathrm{a}$ & $6,035 \mathrm{a}$ & $86,1 \mathrm{a}$ & $2,76 \mathrm{a}$ & $167,05 \mathrm{a}$ & $76,81 \mathrm{a}$ \\
\hline BR29 & $36 \mathrm{a}$ & $376,0 \mathrm{a}$ & $5,733 \mathrm{a}$ & $82,5 \mathrm{a}$ & $2,73 \mathrm{a}$ & $156,17 \mathrm{a}$ & $69,69 \mathrm{a}$ \\
\hline UFLA03-320 & $24 \mathrm{~b}$ & $293,3 \mathrm{a}$ & $5,330 \mathrm{a}$ & $74,3 \mathrm{a}$ & $2,96 \mathrm{a}$ & $159,74 \mathrm{a}$ & $60,06 \mathrm{a}$ \\
\hline UFLA03-321 & $29 \mathrm{a}$ & $286,3 \mathrm{a}$ & $5,713 \mathrm{a}$ & $80,4 \mathrm{a}$ & $3,06 \mathrm{a}$ & $175,10 \mathrm{a}$ & $66,50 \mathrm{a}$ \\
\hline P valor & 0,0281 & 0,0008 & 0,8895 & 0,8173 & 0,0000 & 0,0027 & 0,5385 \\
\hline CV (\%) & 22,4 & 5,1 & 17,0 & 15,7 & 11,8 & 21,0 & 17,0 \\
\hline
\end{tabular}

${ }^{(1)}$ Médias seguidas de letras iguais, nas colunas, não diferem entre si, pelo teste Scott-Knott, a $5 \%$ de probabilidade. 
houve diferença significativa para MSPA e altura, em que os tratamentos em Latossolo Vermelho-Amarelo apresentaram os maiores valores (Tabela 4), fato que também pode estar relacionado à acidez e à menor fertilidade do Cambissolo, o que afetou o desenvolvimento da planta.

No ensaio de campo, realizado em Lavras, houve diferença significativa apenas para NN e

Tabela 4. Massa de matéria seca da parte aérea (MSPA) e altura em guandu-anão cultivar Iapar 43 (Aratã), para os diferentes solos e tratamentos, em casa de vegetação ${ }^{(1)}$.

\begin{tabular}{lcc}
\hline Tratamento & MSPA (g por vaso) & Altura $(\mathrm{cm})$ \\
\hline$+\mathrm{N}\left(300 \mathrm{mg} \mathrm{dm}^{-3}\right)$ & $6,695 \mathrm{a}$ & $65,14 \mathrm{a}$ \\
$-\mathrm{N}$ & $5,431 \mathrm{~b}$ & $66,41 \mathrm{a}$ \\
$\mathrm{BR} 2003$ & $5,225 \mathrm{~b}$ & $62,69 \mathrm{a}$ \\
BR2801 & $5,616 \mathrm{~b}$ & $66,71 \mathrm{a}$ \\
BR29 & $5,328 \mathrm{~b}$ & $68,24 \mathrm{a}$ \\
UFLA03-320 & $4,870 \mathrm{~b}$ & $55,72 \mathrm{a}$ \\
UFLA03-321 & $5,324 \mathrm{~b}$ & $64,51 \mathrm{a}$ \\
\hline P valor & 0,0168 & 0,3585 \\
\hline Solo & & \\
Cambissolo & $5,186 \mathrm{~b}$ & $59,92 \mathrm{~b}$ \\
Latossolo Vermelho-Amarelo & $5,811 \mathrm{a}$ & $68,48 \mathrm{a}$ \\
\hline P valor & 0,0172 & 0,0058 \\
CV (\%) & 17,0 & 17,0 \\
\hline
\end{tabular}

${ }^{(1)}$ Médias seguidas de letras iguais, nas colunas, não diferem entre si, pelo teste Scott-Knott, a 5\% de probabilidade.
MSN quanto aos parâmetros avaliados na floração (Tabela 5). As estirpes UFLA 03-320 e UFLA 03-321 apresentaram maior nodulação e MSN do que os demais tratamentos. A estirpe UFLA 03-321 também apresentou alta nodulação no experimento em vaso com Latossolo Vermelho-Amarelo. Com relação aos parâmetros avaliados por ocasião da colheita, não houve diferença nos tratamentos com inoculação. A produtividade foi superior a $1.100 \mathrm{~kg} \mathrm{ha}^{-1}$ para todos os tratamentos. No presente trabalho a produtividade média de grãos foi de $1.287 \mathrm{~kg} \mathrm{ha}^{-1}$, superior à obtida por Cesar et al. (2011), de $600 \mathrm{~kg} \mathrm{ha}^{-1}$, no Cerrado do Mato Grosso do Sul, e próxima à média mundial de $1.354,9 \mathrm{~kg} \mathrm{ha}^{-1}$ (Food and Agriculture Organization of the United Nations, 2012).

No presente trabalho, mostrou-se a presença de BFNN nativas, nos solos onde foram instalados os experimentos, capazes de nodular e promover o crescimento do guandu-anão. Mostrou-se também a eficiência das populações nativas, o que provavelmente está associado às boas condições de fertilidade e matéria orgânica do solo, que permitiram às estirpes nativas seu estabelecimento e sobrevivência. Populações nativas de BFNN superiores a 50 células por grama de solo podem afetar a resposta à inoculação (Moreira \& Siqueira, 2006). Nos solos usados no presente estudo, as populações eram superiores a esse valor.

Tabela 5. Número de nódulos (NN), massa de matéria seca de nódulos (MSN) e de parte aérea (MSPA), eficiência relativa (ER), teor (TNPA) e acúmulo de $\mathrm{N}$ na parte aérea (ANPA), massa de $\mathrm{N}$ disponibilizado $\left(\mathrm{kg} \mathrm{ha}^{-1}\right)$, número de vagens/planta, número de grãos/vagem, massa de 100 grãos, rendimento, teor (TNG) e acúmulo de $\mathrm{N}$ nos grãos (ANG), em guandu-anão cultivar Iapar 43 (Aratã), nos tratamentos em condições de campo ${ }^{(1)}$.

\begin{tabular}{|c|c|c|c|c|c|c|c|c|c|c|c|c|c|}
\hline Tratamento & $\begin{array}{l}\text { NN por } \\
\text { planta }\end{array}$ & $\begin{array}{c}\text { MSN } \\
\text { (mg por } \\
\text { planta) }\end{array}$ & $\begin{array}{l}\text { MSPA } \\
\text { (g por } \\
\text { planta) }\end{array}$ & $\begin{array}{l}\text { ER } \\
(\%)\end{array}$ & $\begin{array}{l}\text { TNPA } \\
(\%)\end{array}$ & $\begin{array}{l}\text { ANPA } \\
\text { (mg por } \\
\text { planta) }\end{array}$ & $\begin{array}{c}\mathrm{N} \\
\left(\mathrm{kg} \mathrm{ha}^{-1}\right)\end{array}$ & $\begin{array}{l}\mathrm{N}^{\circ} \text { vagens } \\
\text { por planta }\end{array}$ & $\begin{array}{c}\mathrm{N}^{\circ} \text { grãos } \\
\text { por } \\
\text { vagem }\end{array}$ & $\begin{array}{c}\text { Massa } \\
100 \text { grãos } \\
(\mathrm{g})\end{array}$ & $\begin{array}{l}\text { Rendimento } \\
\left(\mathrm{kg} \mathrm{ha}^{-1}\right)\end{array}$ & $\begin{array}{l}\mathrm{TNG} \\
(\%)\end{array}$ & $\begin{array}{c}\text { ANG } \\
\left(\mathrm{kg} \mathrm{ha}^{-1}\right)\end{array}$ \\
\hline$+\mathrm{N}\left(70 \mathrm{~kg} \mathrm{ha}^{-1}\right)$ & $7 \mathrm{~b}$ & $108,4 b$ & $33,33 \mathrm{a}$ & $100,0 \mathrm{a}$ & $4,03 \mathrm{a}$ & $1346,55 \mathrm{a}$ & $96,95 \mathrm{a}$ & $151 \mathrm{a}$ & $2,2 \mathrm{a}$ & $7,54 \mathrm{a}$ & $1568,0 \mathrm{a}$ & $4,13 \mathrm{a}$ & $64,83 \mathrm{a}$ \\
\hline$-\mathrm{N}$ & $6 b$ & $67,2 b$ & $19,40 \mathrm{a}$ & $62,2 \mathrm{a}$ & $3,81 \mathrm{a}$ & $745,09 \mathrm{a}$ & $53,65 \mathrm{a}$ & $117 \mathrm{a}$ & $2,7 \mathrm{a}$ & $6,85 \mathrm{a}$ & $1152,0 \mathrm{a}$ & $4,20 \mathrm{a}$ & $48,21 \mathrm{a}$ \\
\hline BR2003 & $8 \mathrm{~b}$ & $90,6 b$ & $23,24 a$ & $76,5 \mathrm{a}$ & $4,13 \mathrm{a}$ & $966,47 \mathrm{a}$ & $69,59 a$ & $100 \mathrm{a}$ & $3,4 \mathrm{a}$ & $7,52 \mathrm{a}$ & $1190,2 \mathrm{a}$ & $4,13 \mathrm{a}$ & $48,93 \mathrm{a}$ \\
\hline BR2801 & $7 \mathrm{~b}$ & $71,3 b$ & $27,68 \mathrm{a}$ & $92,7 \mathrm{a}$ & $3,93 \mathrm{a}$ & $1090,31 \mathrm{a}$ & $78,50 \mathrm{a}$ & $142 \mathrm{a}$ & $2,3 \mathrm{a}$ & $7,69 \mathrm{a}$ & $1308,9 \mathrm{a}$ & $3,87 \mathrm{a}$ & $48,81 \mathrm{a}$ \\
\hline BR29 & $7 b$ & $85,9 b$ & $23,40 \mathrm{a}$ & $77,8 \mathrm{a}$ & $3,67 \mathrm{a}$ & $868,46 a$ & $62,53 \mathrm{a}$ & $97 \mathrm{a}$ & $2,4 \mathrm{a}$ & $7,36 \mathrm{a}$ & $1229,5 \mathrm{a}$ & $4,10 \mathrm{a}$ & $50,01 \mathrm{a}$ \\
\hline UFLA03-320 & $12 \mathrm{a}$ & $185,0 \mathrm{a}$ & $31,12 \mathrm{a}$ & $100,6 \mathrm{a}$ & $3,54 \mathrm{a}$ & $1101,05 \mathrm{a}$ & $79,28 \mathrm{a}$ & $132 \mathrm{a}$ & $2,2 \mathrm{a}$ & $7,12 \mathrm{a}$ & $1408,0 \mathrm{a}$ & $4,19 \mathrm{a}$ & $58,91 \mathrm{a}$ \\
\hline UFLA03-321 & $13 \mathrm{a}$ & $232,8 \mathrm{a}$ & $20,51 \mathrm{a}$ & $68,6 \mathrm{a}$ & $3,45 \mathrm{a}$ & $706,43 \mathrm{a}$ & $50,86 a$ & $126 a$ & $3,2 \mathrm{a}$ & $7,38 \mathrm{a}$ & $1149,7 \mathrm{a}$ & $4,19 \mathrm{a}$ & $48,37 \mathrm{a}$ \\
\hline $\mathrm{P}$ valor & 0,0268 & 0,0046 & 0,0941 & 0,1302 & 0,2481 & 0,1128 & 0,1128 & 0,4942 & 0,1179 & 0,0564 & 0,5337 & 0,5054 & 0,4157 \\
\hline CV (\%) & 16,7 & 4,5 & 28,2 & 26,6 & 11,0 & 32,3 & 32,3 & 34,2 & 25,6 & 4,8 & 25,7 & 5,9 & 24,2 \\
\hline
\end{tabular}

${ }^{(1)}$ Médias seguidas de letras iguais, nas colunas, não diferem entre si, pelo teste Scott-Knott, a 5\% de probabilidade. 


\section{Conclusões}

1. A estirpe UFLA 03-320 é eficiente em promover o crescimento do guandu-anão 'Iapar 43' (Aratã) e, portanto, tem potencial para ser utilizada como inoculante para a cultura junto com a estirpe BR 2801.

2. Os dois solos utilizados têm populações nativas de BFNN eficientes, com destaque para o Latossolo Vermelho-Amarelo.

\section{Agradecimentos}

Ao Ministério de Agricultura Pecuária e Abastecimento (Mapa), ao Conselho Nacional de Desenvolvimento Científico e Tecnológico $(\mathrm{CNPq})$ e à Coordenação de Aperfeiçoamento de Pessoal de Nível Superior (Capes), pelo financiamento do projeto e pela concessão de bolsas de estudos.

\section{Referências}

ANAND, R.C.; DOGRA, R.C. Comparative efficiency of Rhizobium/Bradyrhizobium spp. strains in nodulating Cajanus cajan in relation to characteristic metabolic enzymes. Biology and Fertility of Soils, v.24, p.283-287, 1997. DOI: 10.1007/ s003740050244.

BIDLACK J.E.; RAO S.C.; DEMEZAS D.H. Nodulation, nitrogenase activity, and dry weight of chickpea and pigeon pea cultivars using different Bradyrhizobium strains. Journal of Plant Nutrition, v.24, p.549-560, 2001. DOI: 10.1081/ PLN-100104979.

BRASIL. Ministério da Agricultura, Pecuária e Abastecimento. Instrução normativa $n^{\circ} 13$ de 24 de março de 2011. Aprova as normas sobre especificações, garantias, registro, embalagem e rotulagem dos inoculantes destinados à agricultura, bem como as relações dos microorganismos autorizados e recomendados para produção de inoculantes no Brasil, na forma dos anexos I, II e III, desta instrução normativa. Diário Oficial da União [da] República Federativa do Brasil, 25 mar. 2011. Seção 1.

CARVALHO, F.G. de; SELBACH, P.A.; SILVA, A.J.N. da. Especificidade hospedeira de variantes Bradyrhizobium spp. em soja (cvs Peking e Clark), caupi e guandu. Revista Brasileira de Ciência do Solo, v.32, p.2701-2708, 2008. DOI: 10.1590/ S0100-06832008000700013.

CESAR, N.Z.; GUERRA, J.G.M.; RIBEIRO, R. de L.D.; URQUIAGA, S.S.C.; PADOVAN, M.P. Performance de adubos verdes cultivados em duas épocas do ano no Cerrado do Mato Grosso do Sul. Revista Brasileira de Agroecologia, v.6, p.159-169, 2011.

COSTA, E.M. da; NÓBREGA, R.S.A.; DE CARVALHO, F.; TROCHMANN, A.; FERREIRA, L. de V.M.; MOREIRA, F.M. de $\mathrm{S}$. Promoção do crescimento vegetal e diversidade genética de bactérias isoladas de nódulos de feijão-caupi. Pesquisa
Agropecuária Brasileira, v.48, p.1275-1284, 2013. DOI: 10.1590/ S0100-204X2013000900012.

CRUZ, C.D. Genes - a software package for analysis in experimental statistics and quantitative genetics. Acta Scientiarum, v.35, p.271-276, 2013. DOI: 10.4025/actasciagron.v35i3.21251.

FERNANDES, M.F.; FERNANDES, R.P.M. Seleção inicial e caracterização parcial de rizóbios de tabuleiros costeiros quando associados ao guandu. Revista Brasileira de Ciência do Solo, v.24, p.321-327, 2000. DOI: 10.1590/S0100-204X2003000700007.

FERNANDES, M.F.; FERNANDES, R.P.M.; HUNGRIA, M. Seleção de rizóbios nativos para guandu, caupi e feijão-de-porco nos tabuleiros costeiros de Sergipe. Pesquisa Agropecuária Brasileira, v.38, p.835-842, 2003. DOI: 10.1590/S0100204X2003000700007.

FERREIRA, D.F. Sisvar: a computer statistical analysis system. Ciência e Agrotecnologia, v.35, p.1039-1042, 2011. DOI: 10.1590/S1413-70542011000600001.

FLORENTINO, L.A.; GUIMARÃES, A.P.; RUFINI, M.; SILVA, K. da; MOREIRA, F.M. de S. Sesbania virgata stimulates the occurrence of its microsymbiont in soils but does not inhibit microsymbionts of other species. Scientia Agricola, v.66, p.667-676, 2009. DOI: 10.1590/S0103-90162009000500012.

FOOD AND AGRICULTURE ORGANIZAZATION OF THE UNITED NATIONS. FAOSTAT. Disponível em: <http://faostat. fao.org/>. Acesso em: 29 nov. 2013.

FRED, E.B.; WAKSMAN, S.A. Laboratory manual of general microbiology: with special reference to the microorganisms of the soil. New York: McGraw-Hill, 1928. 145p.

GUIMARÃES, A.A.; JARAMILLO, P.M.D.; NÓBREGA, R.S.A.; FLORENTINO, L.A.; SILVA, K.B.; MOREIRA, F.M.S. Genetic and symbiotic diversity of nitrogen-fixing bacteria isolated from agricultural soils in the western Amazon by using cowpea as the trap plant. Applied and Environmental Microbiology, v.78, p.6726-6733, 2012. DOI: 10.1128/AEM.01303-12.

HOAGLAND, D.R.; ARNON, D.I. The water culture method for growing plants without soil. Berkeley: California Agricultural Experiment Station, 1950.32p. (California Agricultural Experiment Station. Circular, 347).

JARAMILLO, P.M.D.; GUIMARÃES, A.A.; FLORENTINO, L.A.; SILVA, K.B.; NÓBREGA, R.S.A.; MOREIRA, F.M.S. Symbiotic nitrogen-fixing bacterial populations trapped from soils under agroforestry systems. Scientia Agricola, v.70, p.397-404, 2013. DOI: 10.1590/S010390162013000600004 .

MALAVOLTA, E.; VITTI, G.C.; OLIVEIRA, S.A. de. Avaliação do estado nutricional das plantas: princípios e aplicações. Piracicaba: Associação Brasileira para Pesquisa da Potassa e do Fosfato, 1989. 201p

MARTINS, L.M.V.; XAVIER, G.R.; RANGEL, F.W.; RIBEIRO, J.R.A.; NEVES, M.C.P.; MORGADO, L.B.; RUMJANEK, N.G. Contribution of biological nitrogen fixation to cowpea: a strategy for improving grain yield in the semi-arid region of Brazil. Biology and Fertility of Soils, v.38, p.333-339, 2003. DOI: 10.1007/ s00374-003-0668-4. 
MOREIRA, F.M.S.; SIQUEIRA, J.O. Microbiologia e bioquímica do solo. 2.ed. Lavras: UFLA, 2006. 729p.

NAUTIYAL, C.S.; HEGDE, S.V.; VAN BERKUM, P. Nodulation, nitrogen fixation, and hydrogen oxidation by pigeon pea Bradyrhizobium spp. in symbiotic association with pigeon pea, cowpea, and soybean. Applied and Enviromental Microbiology, v.54, p.94-97, 1988.

PAZ, L.G. da; LUPCHINSKI, E.W.L.; SANTOS, M.V.F. dos; SILVA, J.A.A. da. Efeito do nitrogênio e estirpes de Bradyrhizobium na fixação do nitrogênio e desenvolvimento do guandu (Cajanus cajan (L.) Millsp.) cv. Fava Larga. Revista Científica de Produção Animal, v.2, p.96-106, 2000.

PERES, J.R.R.; VIDOR, C. Seleção de estirpes de Rhizobium japonicum e competitividade por sítios de infecção nodular em cultivares de soja (Glycine max (L) Merrill). Agronomia Sulriograndense, v.16, p.205-219, 1980.

POTH, M.; LAFAVRE, J.S.; FOCHT, D.D. Quantification by direct ${ }^{15} \mathrm{~N}$ dilution of fixed $\mathrm{N}_{2}$ incorporation into soil by Cajanus cajan (pigeon pea). Soil Biology and Biochemistry, v.18, p.125-127, 1986. DOI: 10.1016/0038-0717(86)90118-5.

RUFINI, M.; FERREIRA, P.A.A.; SOARES, B.L.; OLIVEIRA, D.P.; ANDRADE, M.J.B. de; MOREIRA, F.M. de S. Simbiose de bactérias fixadoras de nitrogênio com feijoeiro-comum em diferentes valores de $\mathrm{pH}$. Pesquisa Agropecuária Brasileira, v.46, p.81-88, 2011. DOI: 10.1590/ S0100-204X2011000100011.
RUFINI, M.; SILVA, M.A.P. da; FERREIRA, P.A.A.; CASSETARI, A.S.; SOARES, B.L.; ANDRADE, M.J.B.; MOREIRA, F.M.S. Symbiotic efficiency and identification of rhizobia that nodulate cowpea in a Rhodic Eutrudox. Biology and Fertility of Soils, v.50, p.115-122, 2014. DOI: 10.1007/s00374-013-0832-4.

SARRUGE, J.R.; HAAG, H.P. Análises químicas em plantas. Piracicaba: USP, 1979. 27p.

SOARES, A.L. de L.; PEREIRA, J.P.A.R.; FERREIRA, P.A.A.; VALE, H.M.M. do; LIMA, A.S.; ANDRADE, M.J.B. de; MOREIRA, F.M. de S. Eficiência agronômica de rizóbios selecionados e diversidade de populações nativas nodulíferas em Perdões, MG: I - caupi. Revista Brasileira de Ciência do Solo, v.30, p.795-802, 2006. DOI: 10.1590/ S0100-06832006000500005.

SOARES, B.L.; FERREIRA, P.A.A.; OLIVEIRA-LONGATTI, S.M. de; MARRA, L.M.; RUFINI, M.; ANDRADE, M.J.B. de; MOREIRA, F.M.S. Cowpea symbiotic efficiency, $\mathrm{pH}$ and aluminum tolerance in nitrogen-fixing bacteria. Scientia Agricola, v.71, p.171-180, 2014. DOI: 10.1590/ S0103-90162014000300001.

SOUZA, F.H.D. de; FRIGERI, F.; MOREIRA, A.; GODOY, R. Produção de sementes de guandu. São Carlos: Embrapa Pecuária Sudeste, 2007. 68p. (Embrapa Pecuária Sudeste. Documentos, 69).

VINCENT, J.M. A manual for the pratical study of the root-nodule bacteria. Oxford: Blackwell Scientific Publications, 1970. 164p. (International Biological Programme Handbook, 15).

Recebido em 15 de janeiro de 2014 e aprovado em 13 de março de 2014 